\title{
FAZER DO VELHO UMA NOVIDADE: as reinvenções dos best-sellers juvenis ${ }^{1}$
}

\author{
Andréa Borges Leão*
}

\begin{abstract}
O artigo organiza um debate sobre a produção literária juvenil associada à venda massiva. Tem o duplo objetivo de conceituar os best-sellers e traçar as linhas históricas de conexão da produção contemporânea com a presença do livro europeu e americano na edição brasileira, desde o século XIX. A formação de um espaço literário nacional foi marcada pela importação de clássicos do patrimônio literário mundial, romances de viagem e de aventura, narrativas sentimentais e contos de fadas orientados pela circulação transatlântica da oferta e do consumo massivo. Os critérios estabelecidos para a análise da obra seriada da escritora Thalita Rebouças, que hoje objetiva o fenômeno best-seller nacional, embasam o argumento de que o livro juvenil, quando pego na lógica da circulação mundial da cultura, lança mão de um retorno temático ao passado, reinventando-se ao fazer do velho sempre uma novidade.
\end{abstract}

Palavras-chave: Best-sellers juvenis. Circulação transnacional da cultura. Série literária. Autoria literária.

\section{INTRODUÇÃO: os fluxos transna- cionais da cultura nacional}

Já publiquei sete livros em Portugal e, em 2012, se tudo correr bem, meus livros serão editados em outros países da Europa e na América Latina. Depois de tantos anos correndo atrás, atingi um milhão (!!) de livros vendidos em 2011. Mas eu ainda quero mais, muito mais. Thalita Rebouças

Até a década de 1980, os escritores, editores e estudiosos da literatura juvenil brasileira buscavam articular um projeto nacional comum alicerçado nas diferenças regionais. ${ }^{2}$ Não se pode desconhecer que os esforços na busca de uma marca nacional como marca identitária correspondiam a um momento de-

\footnotetext{
* Universidade Federal do Ceará - UFC. Departamento de Ciências Sociais. Programa de Pós-Graduação em Sociologia. Av. da Universidade, 2995. Cep: 60.020-181. Benfica - Fortaleza - Ceará - Brasil. aborgesleao@gmail.com

${ }^{1}$ Devo essa expressão a Jean-Marc Gouanvic, que a publicou no texto "Traduire/adapter les classiques de la littérature 'populaire' américaine en français, ou de l'art de faire ‘du neuf avec du vieux’”. In: Sapiro, Gisèle (sous la direction). Les Contradictions de la Globalisation Éditoriale.

${ }^{2}$ Note-se que, no Brasil, os estudos críticos da literatura infantil e juvenil são tardios e dispersos. Marco inicial é o livro de Leonardo Arroyo, Literatura Infantil Brasileira, publicado Melhoramentos em 1968.
}

cisivo na luta pela constituição e autonomia de um espaço para o livro infantil e juvenil. Monteiro Lobato, Orígenes Lessa e toda a geração de escritores surgida nos anos 1970 e 1980, a exemplo de Ruth Rocha, Ana Maria Machado, Ziraldo, Marina Colasanti, entre outros, foram importantes artífices desse movimento. Só assim os caminhos seriam pavimentados para o amadurecimento do gênero e a profissionalização do trabalho literário. Hoje, os infantojuvenis - recriados muito mais como um gênero da edição do que da literatura - são as melhores vendas das editoras, além de objetos de políticas públicas, apostas e investimentos comerciais em traduções para o mercado mundial. Os produtores já não se movem mais em função das disputas simbólicas em torno do livro nacional. As oposições entre o nacional e o importado, o popular e o canônico, perderam forças ou, ao menos, foram levadas a se redefinir, e a presença das traduções se impõe como modelo, não provocando mais tanto conflito e tensão ${ }^{3}$ (Fundação..., [20--]).

${ }^{3}$ A Fundação Nacional do Livro Infantil e Juvenil (FNLIJ), importante instância de mediação crítica, promove concursos e atribui selos de qualidade e excelência literária aos livros produzidos no Brasil. Sua atuação em prol da 
Desde o século XIX, a formação de um espaço literário nacional foi marcada pela importação de clássicos do patrimônio universal, romances de viagem e de aventura, narrativas sentimentais e contos de fadas europeus orientados pela circulação transatlântica da oferta de países como França, Portugal e Inglaterra, e pelo consumo massivo incrementado pelos novos leitores das ex-colônias americanas. Por sua vez, os escritores brasileiros também cruzaram fronteiras. A obra de José Mauro de Vasconcelos, autor do best-seller O Meu Pé de Laranja Lima, publicado em 1968, abre um profícuo debate sobre a dimensão transatlântica do que se constrói como ficção no plano local, além de reequilibrar os termos da oposição entre sucesso comercial e legitimidade literária. Em 1978, a editora francesa Stock forma a coleção de livros de bolso Mon bel oranger com as traduções dos romances de Vasconcelos, que conhecem um sucesso absoluto ${ }^{4}$ (Avignon off, 2015). A não equivalência linguística e as forças desiguais implicadas nas trocas e empréstimos entre espaços literários nacionais, a exemplo das que organizam, ainda hoje, a carreira internacional do escritor brasileiro na França, permitem observar processos de formação literária em constituição nos dois países. Não se pode perder de vista, no entan๑ to, que as circulações dos livros no mercado స्. mundial de bens simbólicos são fortemente Фं assimétricas, como lembram Sapiro, Pacouret e Picaud (2015), com a tendência à hegemonia

कீ formação da leitura literária a leva a conhecer uma parte

. dos livros publicados no Brasil. Esses conflitos e tensões,

$>$ no entanto, aparecem em algumas diretrizes e tomadas de

ö posição da FNLIJ.

¿ ${ }^{4}$ Sobre o percurso longevo e atual da obra de José Mauro de Vasconcelos na França, gostaria de destacar a adapta-

- cão de $O \mathrm{Meu}$ Pé de Laranja Lima, traduzido como Mon

Bel Oranger, para o teatro juvenil de marionetes, em 2015,

da companhia de teatro para jovens Théâtre De La Courte

Échelle. Sobre a apresentação festival "Avignon off 2015".

Disponível em: https://compagnieaffable.wordpress.

com/2015/05/29/le-programme-du-festival-davignon-off2015-est-en-ligne/. traçar as linhas de suas conexões, na história da edição juvenil brasileira, com a presença do livro europeu. Nos dias que correm, cada vez mais os produtores se orientam por uma concepção de campo literário em escala internacional, sobretudo face à intensificação das trocas decorrentes da concentração de grupos editoriais. Pode-se afirmar que a circulação transnacional dos livros e impressos publicados na Europa é um traço comum entre a atualidade e o passado.

No segundo tempo da discussão, a obra seriada da escritora Thalita Rebouças, que objetiva o fenômeno best-seller, é situada nas diferenças e continuidades das estratégias, alvos de conquista e trajetórias para a profissionalização literária. A autora de sucesso, que bateu a casa do milhão na venda de exemplares $^{5}$ (Thalita, [20--]), circula desenvolta entre os mundos da literatura, do teatro, do cinema, da televisão, do futebol e do carnaval, inventando uma posição literária de fronteira, como forma de aquisição de valor. Observando suas estratégias de aquisição de valor e afirmação de visibilidade, pode-se dizer que as fronteiras do campo literário são reposicionadas. Os critérios metodológicos estabelecidos para a análise embasam o argumento de que os livros best-sellers, pegos na lógica da circulação mundial da cultura, lançam mão de um retorno temático ao passado, reinventando-se ao fazerem do velho uma novidade. O trabalho dos agentes da circulação do livro, vinculados ou não ao mundo oficial - agentes literários, tradutores, livreiros, editores, diretores de coleção, professores - ganha protagonismo, assim como a balança de trocas e apropriações entre as mais diversas línguas nacionais. A relação dessa produção ficcional com as instâncias de legitimidade e mediações da literatura também se redefine. Tudo leva a crer que os escritores em posição best-seller tendem a dispensar os mediadores que portam competências intelectuais específicas, caso da crítica especializada.

5 Thalita Rebouças atinge a marca de 1 milhão de livros vendidos em 2011, com a série Fala Sério. 
Outro ponto de deslocamento relacionado ao precedente concerne ao público de leitores. Situados em blogs na esfera digital, agrupados ou individualmente, os jovens leitores de best-sellers são chamados a exercer funções críticas, são autorizados e autorizam-se a interpretar e a comentar as narrativas a partir de suas próprias categorias de julgamento estético em formação, uma vez que as fronteiras entre o mundo do livro, o mundo do autor e seus próprios mundos se esgarçam a cada novo lançamento, a cada nova postagem dos editores nas redes sociais, a cada nova aparição pública de escritores celebridades.

Valérie Beaudouin (2012) argumenta não se tratar propriamente da dispensa ou supressão de mediadores especializados, mas de uma redefinição nas formas de mediação e julgamento, quando autores, sobretudo os que atuam nos espaços de escrita da web, inscrevem os leitores - e até seus próprios pares - nos territórios da crítica profissional. Para esta autora, fica difícil uma simples projeção do campo literário, tal como definiu Bourdieu (1996), no espaço digital de produção da escrita.

Se toda cultura nacional é um mundo de conexões históricas transnacionais, o estudo dos best-sellers contemporâneos juvenis requer cronologia mais alargada. Os elos com a tradição literária, convocados por uma sociologia processual da circulação simbólica (Elias, 1994), que privilegia operações lógicas e afetivas nas construções de repertórios de textos separados no tempo e no espaço, organiza metodologicamente a reflexão. Para estudar a literatura juvenil na perspectiva das conexões históricas, é preciso ir além da parte mais visível e atual do mercado: o dinamismo e as inovações dos produtores, que sabem tirar proveito da moda inaugurada pela série de sucesso Harry Potter, de J. K. Rowling. É preciso introduzir uma reflexão sobre as transferências, trocas e empréstimos culturais efetivados no longo prazo.

\section{QUANDO OS BESTS TORNAM-SE LONG-SELLERS}

Um livro best-seller destinado a jovens leitores pode transforma-se em long-seller, ou até em clássico, adquirindo estabilidade pelo êxito das vendas, a depender do teor do que se configura como legitimidade, leia-se visibilidade pela repetição do consumo, conquistado pelo texto e pelo autor face aos leitores-fãs (Heinich, 2012). Por isso, a questão mais importante para a definição do livro best-seller não pode ser reduzida ao êxito comercial. $\mathrm{O}$ prestígio literário que reveste ou não uma obra e a figura do autor é o critério fundamental na classificação desse gênero do impresso. Os índices de prestígio são alcançados pelo reconhecimento do público massivo e, em decorrência, emergem novas exigências de originalidade e singularidade, tanto no texto escrito como no estatuto da autoria literária. Nesse caso, os prêmios das instituições literárias e os selos de indicações de usos nas escolas são atributos apenas complementares de reconhecimento. Não que os best-sellers juvenis sejam livros publicamente condenáveis. Simplesmente inexistem em certos espaços de mediações críticas porque são desconsiderados como ficção literária. Uma pergunta se impõe: a que se deve o silêncio histórico dos estudiosos, mediadores tão importantes nas classificações da ficção juvenil?

As melhores vendas apresentadas periodicamente nas listas dos infantojuvenis publicadas na grande imprensa e sites especializados não delimitariam as obras, sob o ângulo de análise da sociologia, a uma classificação meramente comercial, sobretudo porque dizem respeito à preferência de milhares de leitores. Uma autora na posição best-seller, situada nas fronteiras entre diversos setores da produção cultural, depende da conquista de visibilidade midiática proporcionada pelas estratégias de publicidade dos grupos editoriais representados por suas obras. Mas, fundamentalmente, depende da cumplicidade dos leitores. Por 
isso, os best-sellers são saudados, para ficar com a observação de Letourneux (2010), como signos do retorno dos jovens às práticas de leitura $^{6}$ (Casa..., [20--]). Desse modo, conquistam respeitabilidade, ao menos no que concerne à educação do gosto de leitores massivos, enquanto seus autores vão perdendo posição aos olhos e julgamentos dos que falam em nome das convenções canônicas da literatura, sendo postos no lugar de educadores, formadores pela via do entretenimento.

Do ponto de vista da crítica literária, o termo best-seller, observa Silvia Borelli (1996, p. 139), "preenche certo número de critérios e requisitos que o separam da literatura culta e erudita”. A classificação editorial, por sua vez, priorizaria critérios quantitativos, encarando o livro como mercadoria sujeita às regras do mercado, com "muito pouca, ou quase nenhuma, densidade literária”, observa a socióloga. Os elementos da linguagem e da narrativa só seriam levados em conta quando úteis para atrair o grande público, quer dizer, para mediar a relação de compra e venda do produto. $\mathrm{O}$ best-seller, sob esse ângulo, não passaria de um livro de melhor venda, oferecido a um mercado homogêneo e sem rumo, como se não importassem os agentes mediadores e as instituições culturais que orientam as escolhas - as livrao rias, as editoras e as escolas - ou os projetos intelectuais que visam a garantir a qualidade dos produtos no mercado. Nessa linha de raciocínio, o mercado seria constituído apenas pela comercialização do livro "procurado e seleciois seriam montadas exclusivamente a partir dos dados de vendas que dispensam as mediações i de especialistas. Ora, quando consultamos as listas dos livros infantojuvenis produzidos no país ${ }^{7}$ (Publish..., 2001), constatamos que boa

${ }^{6}$ Ver trechos de entrevistas publicadas no site da escritora

Thalita Rebouças, que ela sugestivamente nomeia de "casa

virtual”. Disponível em: http://thalita-reboucas.blogspot. com.br/2009/01/que-cena-mae.html.

${ }^{7}$ Foram consultadas, entre os anos de 2013 e 2015, as seguintes fontes: jornal Folha de São Paulo, revista Veja e site Publishnews. Disponível em: http://www.publishnews.com.br parte se destina à compra e distribuição pelo governo federal e pelos governos estaduais, a exemplo do Programa Nacional do Livro Didático (PNLD), e do Programa Nacional Biblioteca da Escola (PNBE). Não se pode perder de vista, nesta discussão, que as escolhas das agências não poderiam ser aleatórias, uma vez que são guiadas por comissões de especialistas.

Ao invés da pura e simples condenação dos best-sellers como gêneros menores, de escritas ligeiras e mecânicas, um caminho possível seria inseri-los nos regimes de historicidade nos quais adquirem sentido, o que permite compreender tanto seus sucessos e suas relações com as instituições de consagração e dominação simbólica como a crítica literária que os condena. O importante, sugere Jean-Yves Mollier (2003), é indagar a história dos sucessos literários do ponto de vista dos produtores e dos leitores: o que se lê em determinados períodos, quais são os usos dos livros na vida cotidiana (distração, instrução, passatempo) e se os best-sellers são fontes de distinção ou de estigmatização para quem os lê ou possui.

Deslocada em relação ao que se poderia chamar longevo paradigma Monteiro Lobato - ainda em uso para definir o escritor de excelência, que representa, a um só tempo, o moderno e a nação -, a geração de escritoras teen, composta por Thalita Rebouças, Paula Pimenta, Patrícia Barboza, Babi Dewet, Bruna Vieira, entre outras, é produto da internacionalização da cultura. As trajetórias dessas jovens mulheres cristalizam o investimento da edição juvenil brasileira no mercado latinoamericano e europeu. E as consequências são ainda maiores. Se Thalita Rebouças passa a ser editada em Portugal, fecha contratos com editoras espanholas e italianas ${ }^{8}$ (Pimenta, 2010), e Paula Pimenta segue em direção aos países de língua espanhola e inglesa, pode-se vislumbrar a constituição de comunidades transnacionais de leitores (em inglês, espanhol, italiano e português), aproximando, por exempo, os tra-

${ }^{8}$ Matéria publicada na revista eletrônica Educar para
Crescer, da Editora Abril, reproduzida da Veja Rio. 
balhos de Paula Pimenta aos da norte-americana Meg Cabot, só para ficar no gênero que mistura romances de sensibilidade do século XVIII, no estilo da inglesa Jane Austen, com recriações dos contos de fadas de Charles Perrault e até das fábulas morais dos irmãos Grimm. As trocas entre os românticos Diário da Princesa (primeiro volume da coleção de Meg Cabot) e o Livro das Princesas (em que colaboram com capítulos Meg Cabot, Paula Pimenta, Lauren Kate e Patrícia Barboza), publicado na coleção Galera Record, da editora Record, supõem a aproximação no gosto, na preferência e na competência, entre categorias nacionais de leitores. Essa pode ser uma revolução simbólica, operada pelas novas mulheres de letras, confirmando a hipótese de que, na lógica da formação dos espaços mundiais, as novidades se fazem com a circulação de velhas fórmulas. Uma das estratégias da internacionalização da cultura, não se pode desconsiderar, é a extensão dos espaços da recepção, lembra Gisele Sapiro (2013).

Do ponto de vista dos nexos transnacionais, as autoras best-sellers, que transbordam as próprias obras e circulam pelas fronteiras das produções culturais nacionais, inaugurando um novo sistema de autoria, apresentam-se, sobretudo, como elásticas. É importante destacar, na dinâmica das circulações, a emergência de autores elásticos, que permitem, com maior facilidade, as transferências entre tradições culturais. Os autores de grande elasticidade ou de grande alcance tornam-se estratégicos por transmitirem valores morais sumários, normas de conduta estabelecidas, e mobilizarem um repertório de sentimentos e emoções previsíveis, complementa Pierre Bourdieu (2009). Se as obras preferidas do público não costumam alimentar projeto de nação, tampouco costumam fixar temporalidades, tanto no que toca aos enredos, que podem se passar em qualquer época, quanto no que diz respeito às suas carreiras editoriais de longa duração. Permanecem por meses e até por anos nas listas dos mais vendidos, acabando por se tornarem long-sellers. Vejamos como isso foi possível, no Brasil.
A vocação exportadora da edição europeia, francesa e inglesa e, em consequência, o intenso movimento das trocas culturais iniciado pela circulação internacional das obras no século XIX, ocupam o centro das atenções dos estudiosos da formação cultural brasileira. As influências, imitações, assimilações ou dependências da cultura brasileira em relação à presença do produto europeu e americano ainda hoje animam as discussões e pontuam as agendas dos pensadores sociais. ${ }^{9}$

Se vistas por outro ângulo, percebe-se que as importações de livros populares franceses, portugueses e ingleses, na sociedade brasileira do século XIX, permitiram decisiva transferência de capital literário, formas narrativas e uma estrutura de aprendizagem a ser adaptada por escritores que destinavam suas obras a um incipiente público juvenil, a exemplo de Figueiredo Pimentel, Júlia Lopes de Almeida, Olavo Bilac, Coelho Neto, Viriato Correa e Paulo Barreto, o João do Rio (Leão, 2012). No caso específico do Brasil, o que poderia ser um projeto de colonização cultural, de pura e simples imposição de modelos, imagens e bens de consumo, permitiu o acúmulo de capital simbólico necessário à autonomia da literatura nacional. Importador de artefatos culturais desde fins do século XIX e por todo o século XX e, agora, no XXI, o Brasil assume um lugar na circulação mundial dos bens simbólicos, de tal modo que os horizontes de expectativas do leitorado, que se ampliaram ainda nos tempos do Império, lançam as bases para o que viria a ser um público de massa.

Os livreiros estrangeiros que imigraram para o Rio de Janeiro a partir de 1850, os irmãos Garnier, os Aillaud, Garroux, Briquiet e Laurrane, investiram no trabalho de difusão de textos europeus clássicos, já de largo sucesso comercial em seus países de origem, apostando na durabilidade de diversos gêneros, vendendo, editando e reeditando, por longos anos,

${ }^{9}$ Gilberto Freyre consagra a esse assunto boa parte da discussão do segundo livro da sua trilogia sobre a formação da sociedade brasileira, Sobrados e mucambos. Consultar: Leão, Andréa Borges, 2014. 
romances para a juventude, a obra de escritores de sucesso, como os franceses Jules Verne e Sophie de Ségur, uma vasta literatura de viagens inglesas, todas as variações do Robinson Crusoé, dos contos de Perrault, dos irmãos Grimm e das viagens de Gulliver. Anos após, empresas nacionais, como as editoras Melhoramentos, Globo e Edições de Ouro, seguem a mesma linha e estratégia, publicando clássicos como Pinóquio, Alice no País das Maravilhas e O Pequeno Príncipe, elenca Laurence Hallewel, em O livro no Brasil (2012). Tudo indica que a contingência das trocas e empréstimos no vasto espaço transatlântico prosseguiu na formação de uma indústria cultural e ainda se faz notar nas reinvenções do século XXI. Assim, torna-se evidente que um dos princípios da formação da esfera literária juvenil brasileira são as incorporações de traduções e adaptações dos clássicos universais. Vale observar que a categoria universal diz respeito aos conteúdos morais das narrativas, fazendo com que suas aplicações práticas sejam um complemento da leitura.

No primeiro momento, a criação de um circuito de importação de obras estrangeiras causou reação adversa. A principal delas foi o movimento de formação de um mercado de obras populares nacionais, escritas, impressas e comercializadas no país, protagonizado pe- los livreiros-editores Pedro da Silva Quaresma : 凶̃ culo XIX e início do século XX. ${ }^{10}$ O livro Para Crianças, uma categoria criada para formar 3 polos, ${ }^{11}$ que podem ou não coincidir sem ser obrigatoriamente excludentes.

Ora, uma obra, quando circula de um país ou continente a outro, adverte Pierre Bourdieu (2009), leva consigo o campo de sua produção. As transferências entre espaços nacionais se fazem por meio de uma série de operações entre agentes sociais, a exemplo da seleção do que merece ser traduzido e publicado e dos que reúnem competência e legitimidade para verter os textos de uma tradição linguística a outra. Tais operações de leitura estão baseadas em categorias de percepção e problemáticas próprias a um campo nacional específico. O trabalho da tradução atribui novos sentidos aos textos. Na lógica das escolhas, as afinidades de gosto de linhas editoriais e títulos podem ser explicadas por homologia de posições entre campos nacionais. As tramas de imposição simbólica ditadas pelas altas posições de escritores e editoras não reconhecem fronteiras, podendo se tornar um dos pontos de convergência entre as esferas nacionais e uma das propriedades do que se poderia chamar de espaços transnacionais de circulação literária. Por exemplo, gigantes e potentes grupos editoriais empreendem negócios e fusões com os grupos brasileiros já estabelecidos no mercado.

Por outro lado, as estratégias de anexação de obras traduzidas ao repertório das coleções e séries juvenis brasileiras têm como objetivo nacionalizar os produtos estrangeiros. A circulação de modelos literários acaba por firmar pactos de leitura que auxiliam a compreensão do sucesso local de aventuras que se passam no Egito antigo, das fantasias medievais com a explosão da magia de fadas, elfos e anões em J. R. R. Tolkien, autor de Senhor dos Anéis, das tramas de Harry Potter, de J. R. Rowling, da novidade dos velhos diários na série Diário de um Banana, de Jeff Kinney, das atualizações da mitologia greco-romana nas traduções de Rick Riordan, entre outros universos e tempos médios

${ }^{11}$ No livro As regras da Arte: gênese e estrutura do campo literário (1996), Pierre Bourdieu estuda a dinâmica da vida literária francesa de meado do século XIX. As adaptacões, usos e abusos que se fazem para as mais diversas esferas literárias nacionais escapam ao projeto do sociólogo. 
vividos por guerreiros, príncipes e princesas, anões e dragões. Não por acaso, o livro Pequeno Príncipe, do francês Antoine Saint-Exupéry, publicado em 1943, é um dos mais traduzidos no Brasil e vem ocupando posição de destaque nas listas dos tops nacionais. Da safra dos bestsellers destaca-se o já citado Meu pé de Laranja Lima, de José Mauro de Vasconcelos, publicado em 1968 e hoje traduzido em 52 línguas, o que aponta para o movimento de internacionalização dos produtos nacionais. Mais recentemente, o mesmo tem acontecido com os sucessos de Thalita Rebouças, Fala sério, na editora Rocco, a partir de 2003, e de Paula Pimenta, Fazendo o meu Filme, lançado pela Gutenberg a partir de 2008. O que é efetivamente necessário compreender é que as publicações em séries criam um amplo e cativo mercado receptivo em torno de heróis e heroínas recorrentes e estão longe de significar apenas obras mecânicas e apressadas.

Situando a posição best-seller de Thalita Rebouças na longa história da publicação dos gêneros contos de fadas e romances populares sentimentais, fica evidente a permanência de velhos modelos literários em um universo cada vez mais orientado pela circulação transnacional de bens simbólicos, sob o domínio acelerado da concentração de grupos editoriais e de grandes redes de livrarias.

\section{THALITA REBOUÇAS, AUTORIA E FRONTEIRAS DA PRODUÇÃO SIMBÓLICA}

Na sessão "Perguntas e Respostas" da "casa virtual" de Thalita Rebouças, o site oficial da escritora, entre várias cartas de leitores perguntando como conseguir a primeira editora e como tornar-se escritor, além dos pedidos de leitura de originais, aparece uma garota perguntando como fazer para entrar no mundo da moda: "Você pode me ajudar a virar modelo?"12 (Rebouças, [20--]). Thalita responde:

${ }^{12}$ As notas e passagens biográficas de Thalita Rebouças foram tomadas do site. Como não existe uma fortuna crítica
"Não, meninas, não conheço absolutamente ninguém do mundinho fashion. Melhor procurar agências de modelos no Google. Boa sorte!”. Para quem ocupa uma posição de fronteira entre os espaços da produção simbólica e não estabelece interlocução com os mediadores especializados, a atenção do público é atraída mais pela distribuição massiva de sua imagem, que modula opiniões e dicas de escrita, observa Nathalie Heinich (2012), do que pelas obras publicadas. A conversa epistolar entre a autora e seus leitores, via internet, não poderia girar em torno de estética, simplesmente porque os jovens estão ainda sendo formados em literatura em escolas que talvez nem os preparem para o trabalho crítico. Para um autor, o que importa, continua a socióloga, no regime de visibilidade contemporânea, não é propriamente a assinatura do nome, mas o rosto e o corpo tornados visíveis em grande escala. O mundo dos livros pode levar às passarelas, já que ambos são parte do mesmo universo fashion construído pelo mundo da autora. Vejamos a seguir.

Ser uma fada pop, emancipada e consciente de suas emoções, sem coações externas para realizar magias, necessitando apenas da boa leitura de um manual, corresponde ao horizonte de expectativas de uma leitora-modelo. É o que expressa a personagem do livro Uma Fada veio me visitar. Publicado pela editora Rocco, na coleção Jovens Leitores, o livro conta a aventura de uma fada de 857 anos, um ser atemporal que atualiza a moda da década de 60 em pleno ano de 2007. Tatu, a fada, surge em um apartamento da zona sul do Rio de Janeiro com a missão de ajudar a adolescente Luna a dar uma lição de moral na orgulhosa Lara, que vê sua rica família desmoronar com a prisão da irmã, Milena, acusada de participar de roubos de obras de arte no exterior. A moral é a de que não se deve julgar os outros pela aparência. Milena caiu no golpe por ter

da obra ou estudo biográfico da escritora, o caminho possível foi recorrer a essa fonte. Tomei todo o cuidado para não cair nas armadilhas da produtora do site, a própria autora, na construção de sua autoimagem. Data de Acesso: 18 de março de 2016. 
acreditado na conversa de um grupo de bandidos que a convidou para uma festa num castelo. Eternamente jovem, aparentando ter 20 anos, a fada Tatu frequenta academia, vê o oprograma "Fadástico" aos domingos, flutua e reaparece, nos capítulos finais, à moda antiga: com uma estrela lilás "carimbada na bochecha”. A mesma estrela que traz a autora na foto que ilustra a orelha do livro, embaraçando o mundo da ficção e a vida de Thalita Rebouças. Essas aproximações entre os dois mundos contribuem para a seguinte estratégia de profissionalização do autor best-seller: a busca de engajamento e cumplicidade do leitor para o exercício de uma função crítica singular, a de comentador nos blogs e redes sociais. Outra estratégia de afirmação da autoridade literária é o encontro com o público nos blocos de carnaval, em torcidas de futebol e séries de televisão, espaços de reconhecineto de Thalita Rebouças. O episódio da série Fala Sério!, Fala Sério, Mãe!, composto de crônicas humoradas, foi adaptado para o seriado As Brasileiras, da Rede Globo, com o nome de A Mãe da Barra. Thalita assinou o roteiro e atuou como atriz.

Jornalista de formação, a carioca Thalita Teixeira Rebouças é a única filha de pai dentista e mãe dona de casa. Cursou a faculdade de direito por dois anos, antes de entrar para o curso de jornalismo, onde se titulou. Particiثั pou da Oficina de Atores da Rede Globo, uma 凶ّ porta de entrada na emissora, e iniciou a carreira de jornalista no jornal Gazeta Mercantil. Na autorrepresentação oferecida na sua casa virtual, vê-se a imagem de uma mulher empreendedora que tem o projeto intelectual de divertir e cativar os fãs, com a marca do humor e da ironia, praticando a crônica como "romances em pílulas", aproximando seus livros das éries de sucesso da televisão.

A publicação seriada define uma literatura em sequencia (em pílulas), cuja função é atrair o leitor com dramas e aventuras de personagens recorrentes em vários episódios de uma mesma e longa narrativa. A depender da ocasião, adverte Letourneux (2010, p. 91), as séries são descritas como um sintoma do triunfo da industrialização da cultura. Em Fala Sério!, iniciada em 2004, no selo Rocco Jovens Leitores, cada episódio da vida da personagem Maria de Lourdes, a Malu, corresponde a um volume. O leitor acompanha o aprendizado da heroína na seguinte ordem de relações: Fala Sério, Mãe!, Fala Sério, Pai!, Fala Sério, Filha!, Fala Sério, Amor!, Fala sério, Amiga!, Fala Sério, professor!.

No blog da autora, o público é chamado a intervir nos textos ainda não publicados no suporte impresso, comentando as tramas precedentes, enviando sugestões para os próximos episódios e para a construção de novos personagens. Forma-se um triângulo amoroso entre autor, leitor e personagem. Além de comentadores, os leitores inspiram a elaboração de novos enredos. Uma visita à "casa virtual" acaba fidelizando-os.

Em função dos e-mails recebidos após as visitas, o que traduz o nível de prestígio alcançado, Thalita resolve oferecer um curso online sobre "como iniciar uma carreira de escritor", ${ }^{13}$ conferindo a si mesma a legitimidade para falar em nome do que é e de como praticar a literatura. No compartimento Quem sou da casa, Thalita propõe o seu lugar no sistema de fronteira simbólica da autoria, onde se lê:

Sou fofa. Pelo menos é o que dizem as boas línguas. Nasci no dia 10 de novembro de 1974, sou carioquésima (daquelas que louvam o Rio e agradecem diariamente por ser de uma cidade tão linda e especial), empolgada, teimosa, escorpiana, portelense, Fluminensesesê!, abracenta, sorridente, chata à beça na TPM, chorona (do tipo ridícula, choro até vendo comercial de detergente), alucinada por sambas e marchinhas de Carnaval, louca por brigadeiro (para comer de colher) e adrenalina - já saltei de pára-quedas e asa-delta algumas vezes - e viciada em algumas séries de TV (Friends, Seinfeld, Sex and The City, Big Bang Theory e Brothers and Sisters são minhas preferidas) (Thalita..., 2016).

A vontade de escrever, declara, nasceu da paixão material pelos impressos. Aos 10 ${ }^{13}$ Disponível em: http://www.iedb.com.br/. 
anos, sonhava em ser "fazedora de livros". Depois de corrigir os textos, preocupava-se com os mínimos detalhes da produção - desenhava, encadernava, grampeava a capa e as folhas. Com esses ingredientes autobiográficos, conquista um lugar de inserção ou paixão na cultura literária juvenil e vai preparando, via internet, a recepção de sua obra.

A carreira literária de Thalita Rebouças começou mesmo em 2001, na Bienal do Livro do Rio de Janeiro, em frente ao estande de sua primeira editora, Ao Livro Técnico. Foi assim, narra a escritora:

Vários autores consagrados estavam presentes, como eu poderia competir com eles? Meu Traição entre amigas era apenas mais um livro naquele universo de títulos disponíveis na Bienal. O estande da minha editora, apesar de bonitinho e bem localizado, era um entre muitos espalhados em dois imensos pavilhões do Riocentro. Se eu quisesse vender livros teria que inventar uma forma de chamar atenção, de aparecer, de me destacar e rápido (Thalita..., 2016).

Nessa tarde, lembrou do tempo em que fazia teatro e começou "a bater palmas, a brincar com quem passava na frente do estande e a anunciar o livro em altos brados, como um vendedor empolgado com o seu produto". Comerciante dela mesma, Thalita Rebouças prepara uma cena literária fora da literatura, dando um rosto a um nome que começaria a circular. O problema por vir seria, lembra Heinich (2012, p. 159), converter o reconhecimento do grande público em valor literário. No relato da atuação, fica evidente o cuidado especial com a didatização de uma imagem que se voltaria para o público juvenil: "logo juntou gente ao meu redor, rindo e escutando, e o livro começou a vender como água no deserto". Ao mesmo tempo em que recupera a "arte das vovós" contadoras de histórias e transmissoras orais, animando rodas de leitores, encarnava outras figuras populares, os mágicos e os comerciantes de feiras, tornando a Bienal um espaço de construção da autoria, como se ela mesma escrevesse um prefácio elogioso a seu livro. Para Thalita Rebouças, a indentidade de uma auto- ra não se restringiria ao mundo da escrita. A partir daí, começa um trabalho independente de divulgação do livro. Dispensou intermediários como mais tarde dispensaria as mediaçãos críticas, e saiu batendo nas portas das grandes redes de livrarias para anunciá-lo, como um caixeiro viajante ou um vendedor de enciclopédias. Não tardou para que a experiência da escritora pop star se transformasse em ficção. Em março de 2003, assina contrato com a editora Rocco para a publicação do seu primeiro best-seller, Tudo por um Pop Star. Esse livro conta as aventuras de três amigas da cidade de Resende, Manu, Gabi e Ritinha. O trio parte em busca dos ídolos de uma banda internacinal que está vindo ao Rio de Janeiro fazer um show, no estádio do Maracanã. O cantor pop Júnior Lima assina um texto de apresentação aos leitores, que provavelmente fazem parte da mesma comunidade de fãs de suas canções.

O universo cor-de-rosa das meninas pop sugere, como hipótese, a filiação atualizada da escritora carioca aos romances populares e sentimentais da série Rosa da coleção Harlequin, que publicava, nos anos 40 e 50 do século XX, histórias açucaradas conhecidas como "romances para moças". Esses romances formavam a sensibilidade das leitoras numa linha de continuidade à recepção feminina de histórias românticas no século XIX. Tudo sem perder o frescor. As interdependências entre o novo e o velho indicam que uma etapa de formação da esfera literária juvenil contém, simultaneamente, sua antecedência e sucessão. Norbert Elias (1998) descortinaria, nesses processos, tendências de civilização que orientariam estruturas de aprendizagem. A obra de Thalita Rebouças conduz a sua interpretação, retrospectivamente, como uma assimilação dos diversos gêneros da literatura popular, desde os contos de fadas, os romances-folhetins do século XIX, os clássicos universais traduzidos e toda a produção destinada ao grande público que marcou a indústria editorial e a cultura de massa no Brasil.

Para Daniel Compère (2011), o romance 
popular nasce no ano de 1836, com o aparecimento do romance-folhetim publicado em capítulos nos jornais franceses. Gênero menor diante da poesia e do teatro, o romance popular voltava-se para a satisfação das expectativas de novos leitores que emergiam com o progresso da alfabetização, as mulheres, os jovens e os trabalhadores. É amplamente difundido graças ao jornal, um meio acessível a todos. Do ponto de vista dos estudos literários, o romance popular inicia a sua carreira por uma não recepção, quer dizer, pela exclusão do repertório das obras legítimas e reconhecidas por instâncias como a crítica e a escola. Assim, continua Compère, os romances populares estão vinculados a um público ampliado, formado pelos progressos da educação e pelo desenvolvimento de novas formas de publicação. O exemplo são as coleções de livros de aventuras e viagens do editor francês Louis Hachette, baratos e de pequenos formatos, feitos para a venda nas estações de trem de Paris. A partir daí, o romance popular foi se diversificando em subgêneros: a ficção-científica, os policiais e westerns, as fantasias, o horror e demais formas sobrenaturais, os sentimentais, os eróticos e a pornografia. Os subgêneros, voltados ao entretenimento dependem dos suportes de difusão e da distribuição comercial ampliada.

Pode-se, então, elaborar a hipótese de que as escritoras em posição best-seller utilizam os blogs e redes sócias da internet do mesmo modo que os escritores de romace-folhetim do século XIX utilizavam o jornal impresso e os das novelas utilizavam as rádios, evidenciando uma linha de sucessão também midi$\dot{2}$ ática (Ortiz, 1988). Vale lembrar, com Marlyse Meyer (1996), a velocidade com que o romance folhetim oitocentista atravessa o Atlântico e passa a circular no Brasil. As traduções das novelas francesas para o Jornal do Comércio eram feitas imediatamente após aparecerem em Paris. Por essas e outras estratégias de circulação, os best-sellers são constantemente reinventados, e a literatura de entretenimento continua um sucesso.
Do mesmo modo, a coletânea de contos O livro das princesas - Novos contos de fadas, publicada pela Galera, do Grupo Editorial Record, em 2013, e na qual colabora a escritora Paula Pimenta, deve muito aos compiladores dos contos populares de fins do século XVII, em especial a Charles Perrault. O livro, que já nasceu duplamente clássico e best-seller, e deve muito à posteridade e às transformações do gênero.

Uma chave de compreensão da carreira de Thalita Rebouças é a que situa sua obra nas reinvenções retrospectivas de uma cultura literária para a juventude. Ou melhor, a que apreende os processos de informalização ${ }^{14}$ (Wouters, 2007) dos comportamentos que investem os livros alinhados em uma dinâmica da produção que atualiza velhas fórmulas editoriais, temas e modelos literários. Os romances de princesas com a nostalgia das aventuras e regressos do heroísmo, as narrativas intimistas de conselhos, diários e cartas, definem uma literatura sentimental, aparentada aos melodramas dos séculos XIX e XX. Não faltam regras e padrões de etiqueta. A permanência, na atualidade, de temas já gastos, como as fadas e outros seres sobrenaturais, evidencia o papel da literatura nos processos de refreamento dos afetos e controle das emoções, conforme identificou Norbert Elias (1994) em estudo clássico baseado no corpus dos livros de boas maneiras. Tudo leva a crer que a civilidade contemporânea é um ponto de encontro com o passado. Os sucessos juvenis, desse modo, ocupam tanto lugares de inserção nos sistemas literários nacionais como se inscrevem no patrimônio universal.

O que explica o sucesso de venda e a reação apaixonada são os pactos de leitura firmados entre autoras e leitores-fãs e um maior controle da produção e distribuição dos livros por parte dos escritores. O meio digital abre ca-

14 Considero processos de informalização,emancipação das emoções nas sociedades contemporâneas. Com a maior flexibilidade e diferenciação dos códigos sociais, as pessoas tornam-se menos rígidas e mais conscientes das restrições sociais. 
minho para uma nova invenção autoral e, por conseguinte, para a redefinição de interesses e reposicionamento dos agentes nos circuitos de produção e recepção. A nova geração de escritoras, sem ambivalências, concebe os livros simultaneamente como obras literárias e produtos à venda. Tudo indica que o acesso à visibilidade como uma marca de reconhecimento converte o sucesso comercial do livro em valor literário. Para elas, o importante é corresponder aos horizontes de expectativas de meninas fãs de princesas e de meninos românticos. Suas atenções não se prendem aos paradoxos do que seja ou não a verdadeira literatura, do que seja o livro nacional ou as fronteiras que separam o centro e as margens na esfera literária brasileira. O dilema do duplo, intelectual e negociante, que marcou a carreira de gerações de escritores em busca de autonomia no interior de um campo, passa longe delas. O desafio da análise é apreender a psicogênese ${ }^{15}$ do leitor previsto nos best-sellers e, em consequência, seguir as pistas explicativas das identificações e preferências de longo prazo. Essas pistas nos levam não apenas às variações no gosto literário, mas também às censuras e proibições veiculadas nas narrativas, à assimilação das regras e ao progressivo relaxamento no manejo das emoções nas práticas de leitura. Como lembra Roger Chartier (2000), o livro impresso é o melhor lugar para o encontro entre a forma material, o texto e o leitor.

Com relação aos leitores, uma última palavra. Deve-se levar em conta que o gênero jovem adulto, no qual boa parte dos best-sellers juvenis são classificados, relaciona-se tanto às injunções das políticas públicas do livro e da leitura, a exemplo do Programa Nacional Biblioteca na Escola (PNBE), como às transformações do mercado editorial transnacional. Os livros destinados a um público leitor que vai dos 12 aos 20 e poucos anos preveem leituras tanto no suporte impresso como na tela

15 Norbert Elias (1994), na teoria da civilização, incorpora a ideia de mudança na estrutura psíquica e cognitiva dos indivíduos, atribuindo a esse fenômeno o termo "psicogênese". do computador, até mesmo a leitura escolar de apoio às "práticas da educação básica" ${ }^{16}$ (Fundo Nacional do Desenvolvimento da Educação, 2012). Diante disso, os usos dos best-sellers juvenis trazem para o debate o problema das novas recepções e modalidades de apropriação (nos blogs de escritores e nas redes sociais), que supõem um gosto estético comum às conexões literárias das séries contemporâneas (aos mesmos heróis e tramas). O leitor entra num universo que se torna familiar e não consegue mais sair dele, passando a viver a continuação dos episódios na pele dos heróis. Esta lógica pode fazer de um best um long seller, traçando os destinos da série Fala Sério! por gerações de leitores ainda por vir.

\section{CONCLUSÕES}

A primeira conclusão é a de que um aspecto comum aos livros eleitos pelo público, dos mais populares aos canonizados, é o desconhecimento de nacionalidades. A força de representação dos best-sellers parece seguir a lógica inversa dos discursos da identidade nacional. Se seus autores escapam à categoria de gênios da nação, talvez isso não se deva unicamente à força da interlocução estabelecida com os leitores. Thalita Rebouças encarna a autoria contemporânea por insistir em encontrar seus leitores nos diversos espaços da produção cultural, prolongando o convívio entre as festas de carnaval e tardes de partidas de futebol com a leitura de textos fáceis de ler e de interessar.

A segunda conclusão é a de que os heróis, heroínas e tramas dos sucessos juvenis continuam seguindo temas abstratos, como amizade, amor, traição, inveja, o que os torna ainda clássicos, por deixarem as temporalidades e espaços nacionais em suspenso. Por isso, prestam-se tão bem a representar processos de

${ }^{16}$ A esse respeito, consultar PNBE. 
nacionalização literários diversificados (afinal, quem conseguiria localizar o planeta de $O P e$ queno Príncipe?). Também se tornam clássicos por força da estabilidade das vendas, permanecendo por anos a fio nos catálogos das editoras. Em consequência, os best-sellers são facilmente traduzidos e adaptados, circulando com desenvoltura de uma língua a outra, de uma dinâmica literária a outra, por entre espaços nacionais, continentes e épocas. Os temas, potencialmente universais, resumiu muito bem Jean-Marc Gouanvic (2009), possuem o condão de fazer do velho sempre uma novidade. O que muda, com a passagem do tempo, são as práticas de leitura de acordo com os modos de vida e as percepções dos leitores.

A terceira conclusão segue aquela a que chegou o sociólogo Renato Ortiz (1988), em análise sobre a consolidação de uma sociedade de mercado no Brasil nos anos de 1970: em uma indústria popular de massa, o contato histórico com os produtos estrangeiros por meio de importações e traduções, diversas vezes pensado como dependência e colonialismo cultural em relação aos países de economias centrais, atesta uma mudança de posição do país periférico no contexto internacional. Esse reposicionamento coincide com a progressiva autonomia da esfera cultural brasileira. Sem desconhecer, é claro, que os espaços internacionais de circulação dos textos não estão orientados por livres trocas, mas por relações de força hierárquicas e desiguais entre agentes e instituições.

A quarta e última conclusão aponta para a necessidade de se fazer um inventário histórico dos sucessos juvenis, considerando as especificidades de cada conjuntura editorial e cada espaço literário, o que exige o exame de uma sequência temporal alongada e capaz de evidenciar as permanências e mutações nos processos de formação do mercado de bens simbólicos. A própria noção de sucesso muda com as preferências de cada público, do mesmo modo que, hoje, as boas vendas devem muito ao alargamento dos circuitos de difusão da publicidade na internet. A leitura dos novos contos de fadas não é simples experiência de retorno ao passado. As mutações da sociedade contemporânea afetam a estrutura das narrativas e a concepção dos personagens, aproximando o universo atemporal da fantasia à sociedade midiática, à tecnologia e à tradição. Tudo leva a crer que existam gêneros ficcionias em estado de latência; de tempos em tempos, com a emergência das indústrias editoriais, eles vêm à tona. O importante é considerar os gêneros literários, sobretudo, como construções do mercado editorial, o que explica os dispositivos de classificação e controle dos textos utilizados pelos agentes da produção. Reunir textos e inventar coleções juvenis também diz respeito às gradações do aprendizado e às formas de divertimento que podem oferecer (Cf. Olivero, 1999). Os critérios de classificação do cânone literário em padrões de excelência, que operam distinções e gradações de literalidade, o que é ou não a boa ficção, pouco ajudam a elucidar o problema. Sendo assim, a compreensão do que sejam obras populares e eruditas, best ou long-seller, é apropriadamente alcançada por meio de uma sociologia processual da circulação simbólica (Elias, 1994), que privilegia operações lógicas e afetivas nas construções de repertórios de textos separados no tempo e no espaço.

Recebido para publicação em 04 de maio 2016 Aceito em 05 de setembro de 2016

\section{REFERÊNCIAS}

ALMEIDA, P. Surge uma nova categoria de leitores: o new adult. 2013. Disponível em: http://www.publishnews.com. $\mathrm{br} / \mathrm{materias} / 2013 / 05 / 28 / 73226$-surge-uma-nova-categoriade-leitores-o-new-adult. Acesso em: 26 mar. 2016.

ARROYO, L. A literatura infantil brasileira. São Paulo: Companhia editora melhoramentos, 1988.

AVIGNON Off 2015. 2015. Disponível em: http://www. larevueduspectacle.fr/Avignon-Off-2015-Mon-beloranger-d-apres-Jose-Mauro-de-Vasconcelos_a1378.html. Acesso em: 25 fev. 2016

BEAUDOUIN, V. Trajectoires et réseau des écrivains sur le web: construction de la notoriété et du marché. Réseaux: industries culturelles et internet: les nouveaux instruments de la notoriété, Paris, v. 30, n. 275, sept./oct. 2012. 
BORELlI, S. H. S. Ação, suspense, emoção: literatura e cultura de massa no Brasil. São Paulo: EDDUC: Estação liberdade, 1996.

BOURDIEU, P. As regras da arte: gênese e estrutura do campo literário. São Paulo: Companhia das letras, 1996.

Les conditions sociales de la circulation internationale des idées. In: SAPIRO, G. L'espace intellectuel en Europe: de la formation des États-nations à la mondialisation XIXe-XXIe siècle. Paris: La découvert, 2009.

CASA virtual. [20--]. Disponível em: http://www.thalita. com/site/quem-sou.html. Acesso em: 20 mar. 2016.

CHARTIER, R. La culture de l'imprimé, avant-propos. In: . Les usages de l'imprimé. Paris: Librairie artheme fayard, 1987

. As práticas da escrita: da renascença ao século das luzes. São Paulo: Companhia das letras, 1991. (História da vida privada, 3 ).

. A Ordem dos livros, autores e bibliotecas na Europa entre os séculos XIV e XVIII. Brasília: UnB, 1994.

. Lectures "populaires": culture écrite et société. In:

L'ordre des livres (XIV - XVIII siècle). Paris: Albin Michel, 1996.

Entre poder y placer: cultura escrita y literatura en la edad moderna. Buenos Aires: Ediciones cátedra, 2000.

Cultura escrita, literatura e história: conversas de Roger Chartier com Carlos Aguirre Anaya, Jesús Anaya Rosique, Daniel Goldin e Antonio Saborit. Porto Alegre: Artmed editora, 2001

COMPÈRE, D. Les romans populaires. Paris: Presses sorbonne nouvelle, 2011.

ELIAS, N. O processo civilizador: uma história dos costumes. Rio de Janeiro: Jorge Zahar, 1994. v. 6.

Como pueden las utopías científicas y literarias

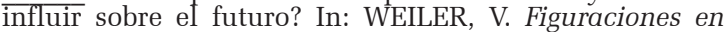
proceso. Santafé de Bogotá: Fundación Social, 1998.

FREYRE, G. Sobrados e mucambos: decadência do patriarcado rural e desenvolvimento do urbano. São Paulo: Global, 2003.

FUNDAÇÃO Nacional do Livro. [20--]. Disponívelem: http://www.fnlij.org.br/. Acesso em: 15 fev. 2016

FUNDO NACIONAL DO DESENVOLVIMENTO DA EDUCAÇÃO. Apresentação. 2012. Disponível em; http://www.fnde.gov.br/programas/biblioteca-da-escola/ biblioteca-da-escola-apresentacao. Acesso em: 15 fev. 2016.

GOUANVIC, J.-M. Traduire adapter les classiques de la littérature "populaire" américaine en français, ou de l'art de faire "du neuf avec du vieux". In: SAPIRO, G. (Dir.) Les contradictions de la globalisation éditoriale. Paris Nouveau monde éditions, 2009. p. 303-313.

HALLEWELL, L. O livro no Brasil: sua história. São Paulo: EDUSP, 2012.

HEINICH, N. De la visibilié: excellence et singularité en régime médiatique. Paris: Éditions gallimard, 2012

IEDB EDUCAÇÃO interativa online. 2009. In: http://www. guiaead.com.br/instituicao/ver/219. Acesso em: 26 mar. 2016.
LEÃO, A. B. Brasil em imaginação: livros, impressos e leituras infantis (1890-1915). Fortaleza: INESP: UFC, 2012. Nós e os franceses: Gilberto Freyre à prova de Adèle Toussaint-Samson. Etnográfica, Lisboa, v. 18, n. 3, p. $625-647,2014$.

LE PROGRAMME du Festival d'Avignon OFF 2015 est en ligne! 2015. Disponível em: https://compagnieaffable. wordpress.com/2015/05/29/le-programme-du-festivaldavignon-off-2015-est-en-ligne/. Acesso em: 20 mar. 2016.

LETOURNEUX, M. Séries, collections et sérialité en littérature pour la jeunesse. La revue des livres pour enfants, Paris, n. 256, dec. 2010.

MEYER, M. Folhetim: uma história. São Paulo: Companhia das letras, 1996.

MOLLIER, J.-Y. Histoire culturelle et histoire littéraire. Revue d'histoire littéraire de la France, v. 103, n. 3, p. 597612, 2003.

OLIVERO, I. L'invention de la collection: de la diffusion de la littérature et des savoirs à la formation du citoyen au XIXe siècle. Paris: Éditions de L'IMEC, 1999

ORTIZ, R. A moderna tradição brasileira: cultura brasileira e indústria cultural. São Paulo: Editora brasiliense, 1988.

PIMENTA, L. Ela atende as meninas. 2010. Disponível em: http://educarparacrescer.abril.com.br/leitura/thalitareboucas-574173.shtml. Acesso em: 5 jan. 2016.

PIMENTA, P. Princesa pop. In: CABOT, M. O livro das princesas: novos contos de fadas. Rio de Janeiro: Editora record, 2013

PUBLISH News. 2001. Disponível em: www.publishnews. com.br. Acesso em: 23 mar. 2016.

REBOUÇAS, T. Uma fada veio me visitar. Rio de Janeiro: Editora rocco, 2007.

Que cena, mãe! 2009. Disponível em: http:// thalita-reboucas.blogspot.com.br/2009/01/que-cena-mae. html. Acesso em: 20 mar. 2016.

Quem sou. [20--]. http://www.thalita.com/site/ quem-sou.html. Acesso em: 18 mar. 2016.

SAPIRO, G. Le champ est-il national? La théorie de la différenciation sociale au prisme de l'histoire globale. Actes de la Recherche en Sciences Sociales, Paris, p. 71-85, déc. 2013.

(Ed.). Translatio: le marche de la traduction en France à l'heure de la mondialisation. Paris: CNRS éditions, 2008.

PACOURET, J.; PICAUD, M. Transformations des champs de production culturelle à l'ère de la mondialisation. In: La culture entre rationalisation et mondialisation. Actes de la Recherche en Sciences Sociales, Paris, p. 5-13, mars, 2015.

THALITA Rebouças. [20--]. Disponível em: http://www4. thalitareboucas.net. Acesso em: 19 mar. 2016.

2016. Disponível em: http://editoras.com/thalitareboucas/. Acesso em: 19 mar. 2016.

WOUTERS, C. Informalization: manners \& emotions since 1890. London: Sage Publications, 2007. 
MAKING THE OLD A NOVELTY: reinventions of children and young adult literature best-sellers

Andréa Borges Leão

This article organizes a debate about the young adult literary production associated to mass production. Thus, the article has the double objective of conceptualizing the best-sellers and tracing the historic lines of connection of the contemporary production with the presence of European and American books in Brazilian edition since the $19^{\text {th }}$ century. The formation of a Brazilian national literary space was marked by the importing of classics of world literary heritage, travel and adventure romances, sentimental narratives and fairy-tales guided by the transatlantic circulation of the offer and the mass consumption. The criteria established for the analysis of the writer Thalita Rebouças' series, which focus on the national bestseller phenomenon today. These criteria supports the argument that the young adult book when following the logic of world culture circulation makes use of a thematic return to the past, reinventing itself by making the old a novelty.

KEYWORDS: Young adult best-sellers. Transnational circulation of culture. Literary series. Literary authorship.

\section{C'EST AVEC DU VIEUX QUE L'ON FAIT DU NEUF: les ré-inventions des best-sellers juvéniles}

Andréa Borges Leão

L’article propose un débat sur la production littéraire juvénile associée aux ventes massives. Il a comme double objectif de conceptualiser les best-sellers et de retracer le lien entre les tendances historiques de la production contemporaine, en prenant en considération la présence des livres européens et américains dans les éditions brésiliennes depuis le XIX ${ }^{e}$ siècle. La formation d'un espace littéraire national a été marquée par l'importation des classiques du patrimoine littéraire mondial, romans de voyage et d'aventure, narratives sentimentales et contes de fées, suivant la tendance de la circulation transatlantique de l'offre et de la demande massives. Les critères établis pour l'analyse de l'oeuvre de l'écrivaine Thalita Rebouças, qui fait actuellement l'objet d'un phénomène national de best-seller, se basent sur l'argument selon lequel les livres juvéniles, lorsqu'ils entrent dans la logique de la circulation mondiale de la culture, ont recours à des thèmes du passé et se réinventent en faisant toujours du vieux quelque chose de neuf.

Mots-CLÉs: Best-sellers juvéniles. Circulation transnationale de la culture. Série littéraire. Auteur littéraire.

Andréa Borges Leão-Doutora em Sociologia pela Universidade de São Paulo. Professora do Departamento de Ciências Sociais e do Programa de Pós-Graduação em Sociologia da Universidade Federal do Ceará. Pós-doutorado em História Cultural, na École des Hautes Études en Sciences Sociales, Paris, sobre as coleções juvenis da Livraria Garnier, e no Centre d'Histoire Culturelle des Sociétés Contemporaines, da Université de Versailles Saint-Quentin-en-Yvelines, sobre as traduções brasileiras dos livros juvenis de Sophie de Ségur e Jules Verne. Integra os grupos de pesquisa CMD (Cultura, Memória e Desenvolvimento) e GECCA (Grupo de Estudos em Cultura, Comunicação e Arte). Desenvolve pesquisas na área da edição e circulação da literatura infantil e juvenil. Atua nos seguintes temas: Sociologia e História Editorial, Práticas Editoriais, Circulação da Cultura e da Literatura, Representações Literárias e Sociologia Histórica da Cultura. Publicações recentes: $O$ popular no Brasil numa fábula de costume francesa: estéticas e mediações transatlânticas. Sociedade e Estado (UnB. Impresso), v. 31, p. 631-650, 2016; Fazer do velho uma novidade: as reinvenções dos best-sellers juvenis. Caderno CRH (UFBA. Impresso), v. 29, p. 463-476, 2016; Ceará, lado moleque (as letras e a sociogênese do humor). Arquivos do CMD, v. 3, p. 1-16, 2015. 